\title{
Binding Ability of Corn Cobs Hemicellulose toward Cadmium
}

\author{
Muchlisyam $^{1 *}$, Urip Harahap ${ }^{1}$, Jansen Silalahi ${ }^{1}$, Zul Alfian ${ }^{2}$ \\ ${ }^{1}$ Faculty of Pharmacy, University of North Sumatera, Medan, Indonesia \\ ${ }^{2}$ Department of Chemistry, Faculty of Mathematics and Natural Sciences, University of North Sumatera, Medan, Indonesia \\ Email: ${ }^{*}$ muchlisyam@gmail.com
}

Received March 27, 2013; revised April 28, 2013; accepted June 15, 2013

Copyright (C) 2013 Muchlisyam et al. This is an open access article distributed under the Creative Commons Attribution License, which permits unrestricted use, distribution, and reproduction in any medium, provided the original work is properly cited.

\begin{abstract}
Non-Starch Polysaccahride (NSP) is an agricultural byproduct containing of cellulose, hemicelluloses, and lignin. Hemicellulose has a hydroxyl functional group and carboxylic function on the monomer hemicellulose used as a binding ability for cadmium ion and hence as a pharmaceutical active ingredient to prevent cadmium toxicity. The purpose of this study is to isolate and evaluate hemicelluloses from corn cobs as a binding ability toward cadmium ion. The study is conducted by isolating the corn cobs in such way using $0.2 \mathrm{M} \mathrm{NaOH}$, characterization of hemicellulose from corn cobs produced by Infra Red Spectrofotometry. Binding ability of corn cobs hemicellulose (CCH) was done in 3 ways. The first, it was by titrimetric with cadmium $3 \mathrm{mg} / \mathrm{cm}^{3}$ as a titrant and indicator of $0.05 \mathrm{~N} \mathrm{NaOH}$. The second, it was by in vitro test at $\mathrm{pH} 2$ as a comparison to use pectin. The third, the in vivo test was conducted in 3 variations of treatment covering CCH $10 \mathrm{mg}, 100 \mathrm{mcg}$ of cadmium for 10 weeks. Assay of cadmium was conducted using atomic absorption spectrophotometry with flame at a wavelength of $228.8 \mathrm{~nm}$. The research result showed that the highest yield of hemicellulose (12.04\%) was obtained from delignication with $0.03 \mathrm{M} \mathrm{NaOH}$ in $60 \%$ ethanol and $3 \% \mathrm{H}_{2} \mathrm{O}_{2}$, hemicellulose isolation with $500 \mathrm{~cm}^{3}$ of $0.2 \mathrm{M} \mathrm{NaOH}$, and precipitation with $1: 4$ ratio of $10 \%$ acetic acid in $95 \%$ ethanol. Characteristics of $\mathrm{CCH}$ on infrared vibration methods provide vibrational hemicellulose in the region of 1820 $1600 \mathrm{~cm}^{-1}$. It meant that the functional group carbonyl was present, and the vibration widened near $3400-2400 \mathrm{~cm}^{-1}$. It indicated that there was the functional group vibration region of hydroxyl. It also meant that there was carboxylic group and finger print at $1500-500 \mathrm{~cm}^{-1}$. Test results of the titrimetric holding ability showed that $\mathrm{CCH}$ was binding $100 \mathrm{mg}$ of cadmium $(46.17 \pm 0.9256) \mathrm{mg}$ or $46.17 \%$. Binding ability test results at $\mathrm{pH} 2$ showed that $300 \mathrm{mg}$ of $\mathrm{CCH}$ yield was binding $30 \mathrm{mg}$ cadmium of $(26.68 \pm 0.1490) \mathrm{mg}$ or $88.93 \%$. The results of in vivo tests showed that cadmium levels decreased by $95.05 \%$. Based on the exposure, it can be concluded that the $\mathrm{CCH}$ isolation yields of $12.04 \%$ and can reduce cadmium levels in the blood. It means that the $\mathrm{CCH}$ can be used as a chelating agent of cadmium ions by in vitro and in vivo.
\end{abstract}

Keywords: Corn Cobs; Hemicellulose; Cadmium Solution; Binding Ability; In Vitro; In Vivo

\section{Introduction}

Cadmium is a heavy metal in a certain amount of time and can affect the development of neural and biological function, and health in general as well. Cadmium toxicity depends on several factors such as the way of how to get into the body, numbers, time exposed to body, age, and health condition of a person. Body exposure to cadmium can be through food, drink, medicine, environment, or at work [1]. Cadmium metal is a dangerous element because it tends to undergo a process of bioaccumulation. The potential toxic amount accumulates within sensitive organs

"Corresponding author. and tissues. In humans, poisoning by most of these metals causes severe dysfunction in the kidneys, reproductive system, liver, brain, and central nervous system [1-3]. The occurrence of various types of diseases above is caused by the levels of cadmium in the body that are above the average level. In relation to this, it needs to be done to reduce the body's exposure to cadmium using the supplemental inert material with no pharmacological effect, meanwhile has the ability to reduce cadmium levels. One effort that can be developed to reduce the amount of cadmium in the body is to harness the potential of natural resources such as agricultural by-product in Indonesia, which acts as a chelating agent for toxic metal in the body. 
Non-Starch Polysaccarides (NSP) is a byproduct of the agricultural material processing which is amounted to around $30 \%-50 \%$ of the total number of processed agricultural products. The largest component of the NSP is the fiber, consisting of components and non polysaccharide, hetero-polysaccharides such as cellulose $(20 \%$ $35 \%)$, hemicellulose $(20 \%-35 \%)$, pectin, alginate and lignin $(10 \%-25 \%)$. By conducting the process of extraction and careful fractionation of biomass byproduct of this material, it will result in various compounds which can be converted into high value products $[4,5]$. Hemicellulose in the pharmaceutical field could potentially be developed as a dietary supplement or as a drug formulation excipient such as chelating agents, disintergrator, thickeners, and stabilizers. In addition, several important applications of hemicellulose have been done by making the derivatives which have pharmacological effects such as lowering cholesterol, and inhibitors of HIV [5-8].

Several researchers have investigated the functional group in organic compounds which are present in nature, such as amine and hydroxyl groups in chitosan, hydroxyl carboxylate groups of sodium alginate, and pectin-containing carboxylic and hydroxyl groups found to adsorb various metals such as aluminum, iron, lead and copper [9-11]. Hemicellulose is one of the most abundant polymer after cellulose. However, its potential has yet to be completely recognized. Hemicellulose comprises a variety of monomers including xylose, mannose, arabinose, glucose, glukoronic acid having carboxylic and hydroxyl group on each monomer [12]. In the qualitative chemical analysis of organic compounds, the hydroxyl group in both cyclical aliphatic will be able to bind to the metal in order to form complex salts.

Corn cob contains a considerable resource of hemicellulose. It contains approximately $12.5 \%$ of hemicellulose and is the largest amount in comparison with other species [12]. Several researches have been performed toward the separation of hemicellulose from different plant byproduct with different methods of isolation. The lignification process was conducted among others by $\mathrm{NaOH}$ in $70 \%$ ethanol, chlorine, sodium hypochlorite and $30 \%$ $\mathrm{H}_{2} \mathrm{O}_{2}$. The Isolation of hemicellulose used alkaline compounds such as $\mathrm{KOH}$ or $\mathrm{NaOH}$ with various concentrations, whereas hemicellulose was used for purification of $\mathrm{HCl}$ and $90 \%$ ethanol $[5,6,12]$.

Based on the terms described above, it is necessary for the research groups found on Corncobs hemicellulose $(\mathrm{CCH})$ to do with an infrared spectrophotometer [13]. Further testing of the groups bonded ability of $\mathrm{CCH}$ as binding metal ions, the acid-base titration between cadmium and hemicellulose at alkaline $\mathrm{pH}$ using $0.05 \mathrm{~N}$ $\mathrm{NaOH}$ indicators [14]. The study made use of hydroxyl and carboxylic groups at corn cobs hemicellulose as a ligand to the metal ion to test its ability as a binding ability towards cadmium ions at $\mathrm{pH} 2$ compared to the pectin, through determination of cadmium levels in the supernatant which was performed by the method of atomic absorption spectrophotometry (AAS) with flame at a wavelength of $228.8 \mathrm{~nm}[3,15,16]$.

Furthermore, this study will also be conducted with trial CCH binding ability in vivo toward cadmium using a rabbit for a period specified [17].

\section{Experimental}

\subsection{Materials}

Corn Cobs were obtained from local corns in Medan, Indonesia. Pectin Technical grade (China), $\mathrm{NaOH}$ (E. Merck), 35\% hydrogen peroxide (E.Merck), 96\% ethanol (E.Merck), acetic acid 98\% (E.Merck), cadmium sulfate (E.Merck), Cadmium ion $1000 \mathrm{ppb} / \mathrm{cm}^{3}$ (E.Merck), and all other chemicals used were of analytical grade.

\subsection{Methods}

\subsubsection{Isolation of Hemisellulose from Corn Cobs}

The extraction method was modified from the combination methods described by $[5,6,12]$. The corn cobs powder of 50 grams was added to $500 \mathrm{~cm}^{3}$ of $0.03 \mathrm{M} \mathrm{NaOH}$ in $70 \%$ ethanol and heated at $60^{\circ} \mathrm{C}$, then stirred for 2 hours to dissolve the lignin. The suspension was allowed to cool to room temperature and filtered through Whatman filter paper. The precipitate was added $500 \mathrm{~cm}^{3}$ of $0.2 \mathrm{M} \mathrm{NaOH}$ and stirred for 8 hours at room temperature to dissolve hemicellulose, and then filtered. The filtrate was heated at a temperature of $65^{\circ} \mathrm{C}$, and added $137 \mathrm{~cm}^{3}$ of $3 \% \mathrm{H}_{2} \mathrm{O}_{2}$ in stages. Each addition of $1 \mathrm{~cm}^{3} 3 \% \mathrm{H}_{2} \mathrm{O}_{2}$ to the filtrate was stirred constantly. Stirring was performed until the entire $3 \%$ of $\mathrm{H}_{2} \mathrm{O}_{2}$ was used and continued to a clear solution. Solution of $10 \%$ acetic acid in $95 \%$ ethanol with a ratio of 1:4 $(\mathrm{v} / \mathrm{v})$ was added to the sample solution and left at room temperature for 6 hours until the precipitate was formed. The suspension was centrifuged at a rate of $10.000 \mathrm{rpm}$ for 15 minutes, and the filtrate was discarded. The precipitate was washed with $96 \%$ ethanol, and dried in vacuum dryer. The washed precipitate is hemicellulose.

\subsubsection{Characterization of Corn Cobs Hemicellulose Using Infrared Spectrophotometry (FTIR)}

Weighed amount of $1 \mathrm{mg}$ hemicellulose and added 200 $\mathrm{mg}$ of potassium bromide, ground to a homogeneous, then analyzed the vibration in the range of wave number $4000-500 \mathrm{~cm}^{-1}$, Infrared spectra recorded the fingerprint spectrum and the spectrum of functional groups resulting from the hemicellulose [13]. 


\subsection{Test to CCH Power Strap Respect for Cadmium (Cd) Ion with Titrimetric in the pH Bases}

\section{Procedure:}

The $\mathrm{CCH}$ was weighed $100 \mathrm{mg}$ and then put in six erlenmeyer, then dissolved in $1 \mathrm{~cm}^{3}$ of $0.05 \mathrm{~N} \mathrm{NaOH}$, diluted with distilled water to $10 \mathrm{~cm}^{3}$, and titrated with a solution $3 \mathrm{mg} / \mathrm{cm}^{3}$ cadmium ion. The end point of the titration is indicated by the formation of white precipitate [14].

\subsection{Identify the Cadmium CCH Titration Results with the Color Reaction}

The results of titration with cadmium $10 \mathrm{mg} / \mathrm{cm}^{3}$ were centrifuged at 10,000 rpm for 15 minutes. Then, the filtrate was separated from sediment, and the sediment was washed with aquades. After that, it was suspended in 1 $\mathrm{cm}^{3}$ of concentrated nitric acid and diluted with $10 \mathrm{~cm}^{3}$ of distilled water and stirred for 2 minutes, then centrifuged and separated. The results of hemicellulose filtrate titration appear and the first reaction solution of potassium sulfide is added to cadmium forming a yellow color [16].

\subsection{Identification by FTIR}

\section{Procedure:}

Titration of the resulting solution was centrifuged and the filtrate was used for identification power strap ability of cadmium by as many as $10 \mathrm{~cm}^{3}$ hemicellulose. Titration results with fried dryer and dry powder weighed as much as $1 \mathrm{mg}$ and were identified by FTIR. The results were compared to the yield of vibrational $\mathrm{CCH}$ with infra red.

\subsection{Cadmium Absorption}

The absorption method was modified from the methods described by [10]. The hemicellulose and pectin respectively weighed $100 \mathrm{mg}, 200 \mathrm{mg}$ and $300 \mathrm{mg}$. Then, each was dissolved into erlenmeyer containing $25 \mathrm{~cm}^{3}$ solution $30 \mathrm{mg} / \mathrm{cm}^{3}$ of cadmium in $0.1 \mathrm{~N}$ nitric acid and the $\mathrm{pH}$ adjusted to acid $\mathrm{pH}$ was performed at $\mathrm{pH} 2$. The solution was stirred with a magnetic stirrer at room temperature for 2 hours.

Then, each was centrifuged at 10,000 rpm for $30 \mathrm{~min}-$ utes. The supernatant was taken and diluted with $0.5 \mathrm{~cm}^{3}$ to $50 \mathrm{~cm}^{3}$ aquabidest; then $0.25 \mathrm{~cm}^{3}$ of dilution was taken and diluted to $25 \mathrm{~cm}^{3}$ with aquabidest and cadmium levels were measured. The cadmium in the supernatant were estimated using flame atomic absorption spectroscopy (Hitachi Analyst 100) at $228.8 \mathrm{~nm}[3,15,16]$. The results are presented as mean values \pm standard deviation.

\subsection{The in Vivo CCH Testing in Rabbits}

The test is performed with the following steps:
1) As many as 15 rabbits were weighed and their blood was drawn to determine the initial level of cadmium in Blood.

2) Rabbits were divided into 3 groups and each group consisted of 4 rabbits. They were given to drink $3 \mathrm{~cm}^{3}$ aquabides and then treated as follows:

\section{Group I}

Rabbits were given 100 mcg of cadmium orally every 2 days for 2 weeks and then as much as $3 \mathrm{~cm}^{3}$ of it was drawn. A total of $1 \mathrm{~cm}^{3}$ was used to determine the levels of cadmium in the blood. Furthermore, it was given $10 \mathrm{mg}$ $\mathrm{CCH}$ together with $100 \mathrm{mcg}$ of cadmium every 2 days. After 2 weeks, as much as $3 \mathrm{~cm}^{3}$ of blood was drawn. It is used to test the results of the implementation of this by checking the cadmium levels in blood samples. And it was held for 10 weeks.

\section{Group II}

Rabbits were given $10 \mathrm{mg} \mathrm{CCH}$ and $100 \mathrm{mcg}$ of cadmium through their mouths every 2 days for 2 weeks and as many as $3 \mathrm{~cm}^{3}$ of blood were drawn to determine the results of treatment by determining the levels of cadmium. The treatment was carried out for 10 weeks.

\section{Group III}

Rabbits were given $10 \mathrm{mg} \mathrm{CCH}$ through their mouths every 2 days for 10 weeks and as many as $3 \mathrm{~cm}^{3}$ of blood were taken every 2 weeks to determine the results of treatment by determining the levels of cadmium. The treatment was carried out for 10 weeks.

Determination of Cadmium Levels in Blood of Rabbits One $\mathrm{cm}^{3}$ of blood was added to $5 \mathrm{~cm}^{3}$ of concentrated nitric acid and heated on a hot plate at a temperature of $150^{\circ} \mathrm{C}$ for 30 minutes. Then, it was added $0.2 \mathrm{~cm}^{3}$ of $50 \%$ perchloric acid solution and $0.4 \mathrm{~cm}^{3}$ of concentrated sulfuric acid and heated in a row at a temperature of $150^{\circ} \mathrm{C}$, $200^{\circ} \mathrm{C}$ and $250^{\circ} \mathrm{C}$ respectively within 15 minutes. Once it was heated at a temperature of $320^{\circ} \mathrm{C}$ for 20 minutes. The results were obtained by the destruction of the white and absorbed in $6 \mathrm{~N} \mathrm{HNO}_{3}(\mathrm{v} / \mathrm{v})$ at a temperature of $90^{\circ} \mathrm{C}$ for 30 minutes until dissolved, and cooled and diluted with mineral-free water [15]. The determination of cadmium levels in a sample of the destruction was done by flame AAS at a wavelength of $228.3 \mathrm{~nm}[3,16,17]$.

\section{Results and Discussion}

\subsection{Isolation of Hemicellulose}

The modified isolation of corn cobs hemicellulose used $500 \mathrm{~cm}^{3}$ of $0.03 \mathrm{M} \mathrm{NaOH}$ in $70 \%$ ethanol and precipitation used the solution of $10 \%$ acetic acid in $95 \%$ ethanol with a ratio of $1: 4(\mathrm{v} / \mathrm{v})$ and corn cobs hemicellulose reached the levels of $12.04 \%$. It is in accordance with the results of Richana's research in 2006 that reached the levels of $12.5 \%$ [12]. 


\subsection{Characterization of Corn Cobs Hemicelluloses}

The characterization of corn cobs hemicellulose includes functional groups and vibrational fingerprint with FTIR and retention time, peak height, area and type symetris by high performance liquid chromatography $[12,14,18]$. The results can be seen in the Table 1.

FTIR characterization of the hemicellulose in Table 1 above shows that the sample of the insulation has a $\mathrm{C}=\mathrm{O}$ group and $\mathrm{OH}$ group. The functional group is present in the monomer on the hemicellulose and the right catchment area of $1500-500 \mathrm{~cm}^{-1}$ is an absorption area of fingerprint region [14] and the sample gives the of vibrations in the fingerprint region which is shown in Figure 1(a).

The HPLC characterization in Table 1 above shows that the sample of retention time, peak height, area and symetric which in Figure 1(b).

At the characterization by HPLC in Table 1 is illustrated in Figure 1(b) indicates that the yield of hemicellulose appears to have hydrophilic properties of hemicellulose by HPLC testing using aquabidest as mobile phase, using a $\mathrm{C} 18$ column, with a flow rate of $0.8 \mathrm{~cm}^{3} /$ min and Ultra Violet light detector at a wavelength of $280 \mathrm{~nm}$ produces retention time of 1.8 , peak height of 5.11558 and symmetrical area of 0.82 .

\subsection{The CCH Bind Power Test Results for Cadmium (Cd) with Titrimetric in the Bases pH}

The test of $\mathrm{CCH}$ ability as a chelating agent metal titrimetric with titration was done indirectly and as a solvent, $0.05 \mathrm{~N} \mathrm{NaOH}$ as much as $1 \mathrm{~cm}^{3}$ was used. This is based on hemicellulose of hydroxyl groups that react

Table 1. Characterization of corn cob hemicelluloses with Solubility, FTIR and HPLC.

\begin{tabular}{lll}
\hline & Aquadest & Poorly soluble \\
Solubility & Hot water & Dissolve \\
& $1 \% \mathrm{HCl}$ & Poorly soluble \\
& $1 \% \mathrm{NaOH}$ & Dissolve \\
\hline \multirow{2}{*}{ FTIR } & Functional groups & Hydroxyl \\
& & Carbonyl \\
& Retention time & 1.802 \\
HPLC & Peak height & 1.06418 \\
& Area & 5.11558 \\
& Symetric & 0.82 \\
\hline
\end{tabular}

with the sodium salt into alkaline salts which are soluble in water. This is in accordance with the legal principles that reactions between Lewis acids and bases will form water-soluble salts $[16,19]$. The titration results of $\mathrm{CCH}$ bond between the metal ions cadmium are shown in Table 2.

Based on Table 2, it appears $100 \mathrm{mg}$ of $\mathrm{CCH}$ was bond cadmium at $(46.88 \pm 0.5094) \mathrm{mg}$. That's mean, that the cadmium ions can release sodium from hemicellulose. Because based on their group in the periodic system, the sodium contained in the class $1 \mathrm{~A}$ and had a low electronegativity compared to cadmium ions in group II. This is reinforced by laws developed by [19], the law of the Hard Soft Acid Base stating the bonding that occurs in hemicellulose also occurs at hydroxyl groups contained in the carboxylate groups and hydroxyl $\mathrm{CCH}$. Although the reaction between sodium, a strong acid and a hydroxyl compound of hemicellulose, a strong base can be replaced by other cations, there are soft acid such as cadmium ions [16].

This indicates that the titration performed in the alkaline $\mathrm{pH}$ of the hemicellulose can bind cadmium with endpoint white precipitation of $\mathrm{Cd}(\mathrm{OH})_{2}$.

\subsubsection{The Identification of Cadmium CCH Bond with Color and FTIR}

The titration reaction of cadmium with $\mathrm{CCH}$ was tested through the identification of specific reactions to cadmium, filtrate, precipitate and the final titration [14]. It appears that there has been a reaction between cadmium and hemicellulose as indicated by the specific reaction of cadmium in the filtrate titration results. Filtrate titration results indicate that sediment has specific color for cadmium. This proves that there has been an ionic bond between the cadmium and $\mathrm{CCH}$ and they form watersoluble complexes. This is also evidenced by the sediment test titration results showing a similar reaction. It means that the deposits were formed in the precipitate titration of cadmium hydroxide. The comparison between infrared vibrational forms of $\mathrm{CCH}$ and the vibrations reaction of $\mathrm{CCH}$ with cadmium can be seen in Figures 1(a) and 2.

Based on Figure 2, it appears that there is a change in the form of vibrations of the corn cobs hemicellulose before (Figure 1) and after the reaction with cadmium (Figure 2). This shows that the inclusion of cadmium ions at $\mathrm{CCH}$ will change the layout of existing vibrations in the corn cobs hemicellulose group. Thus, it generates the vibration of the bonds between hemicellulose and cadmium. $\mathrm{OH}$ vibrations in the region of $3700 \mathrm{~cm}^{-1}$ to 3000 $\mathrm{cm}^{-1}$ change the amount of vibration and the vibration between hemicellulose bond and cadmium in the form of vibrations extends to $3382.84 \mathrm{~cm}^{-1}$ which is a carboxylate vibrations of hydroxy groups. But, it is no longer in bonds 


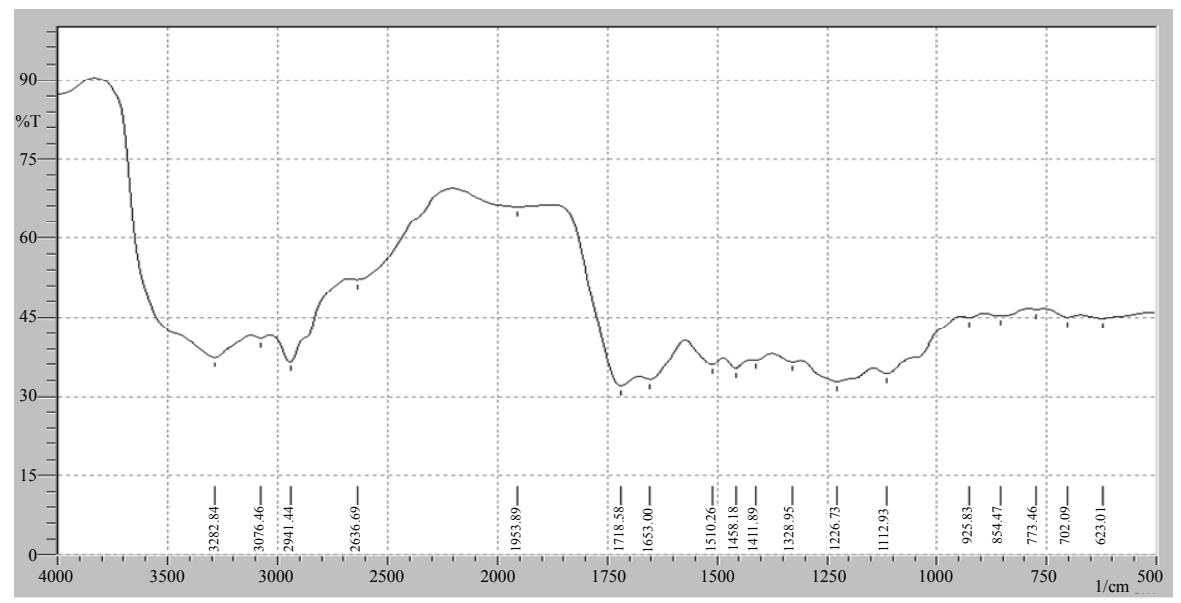

(a)

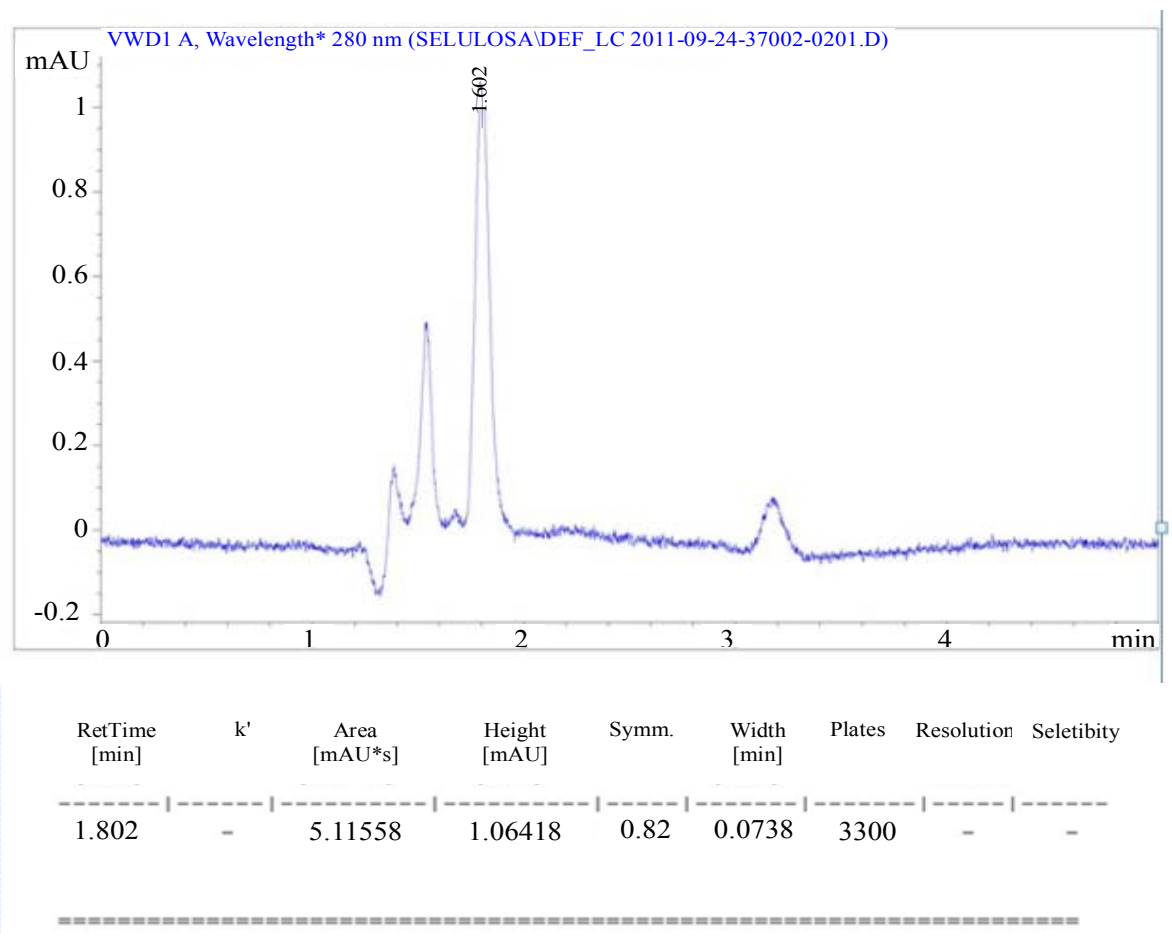

(b)

Figure 1. (a) Characterization infra red vibration of corn cobs hemicellulose; (b) Characterization corn cobs hemicellulose by high performance liquid chromatography (HPLC).

Table 2. Titration results corn cobs hemicellulose with cadmium $3 \mathrm{mg} / \mathrm{cm}^{3}$ as a titrant.

\begin{tabular}{cccc}
\hline No. & Corn Cobs Hemicellulose $(\mathrm{mg})$ & Volume $3 \mathrm{mg} / \mathrm{cm}^{3} \mathrm{Cd}_{\left(\mathrm{cm}^{3}\right)}$ & Percentage $(\%)$ \\
\hline 1 & 100.4 & 15.65 & 46.51 \\
2 & 100.7 & 16.05 & 47.46 \\
3 & 101.4 & 16.20 & 47.23 \\
4 & 101.7 & 15.90 & 46.11 \\
5 & 101.9 & 16.35 & 47.20 \\
6 & 101.7 & 16.15 & 46.80 \\
& & & 46.88 \\
\hline
\end{tabular}




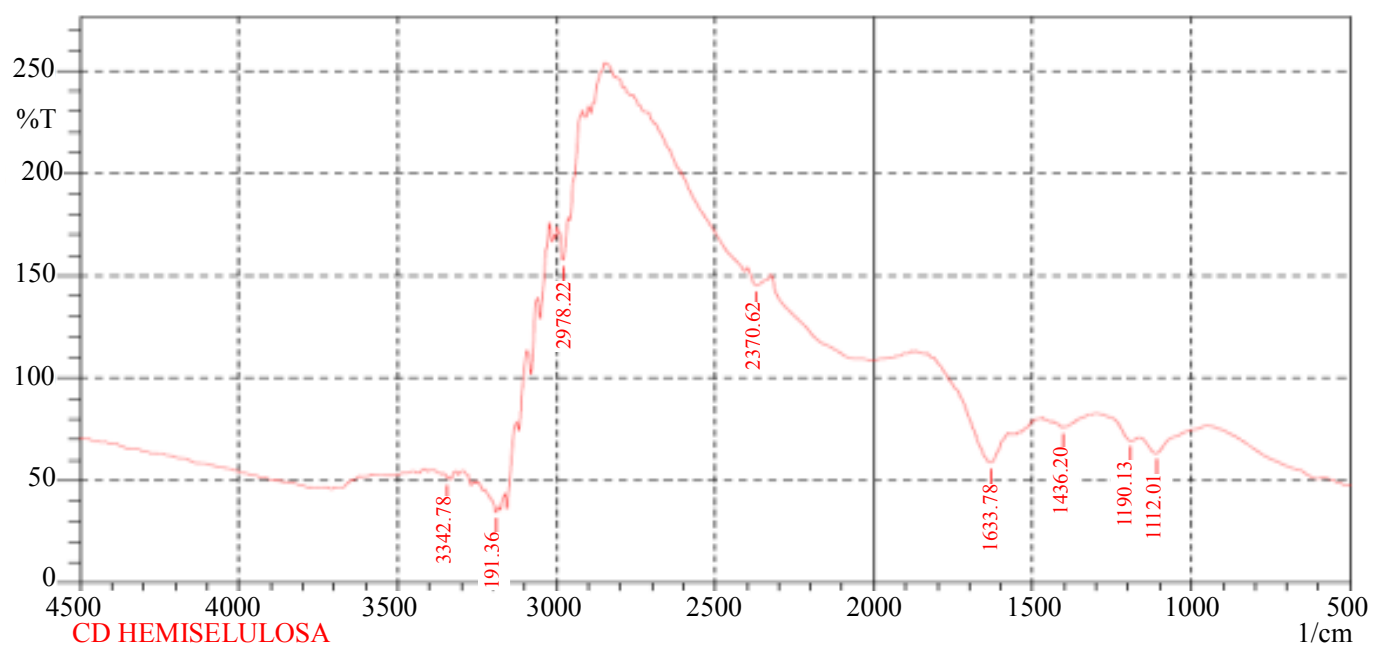

Figure 2. Characterization infrared vibration of $\mathrm{CCH}$ and cadmium complex.

between hemicellulose and cadmium. It means that carboxylic groups on the hemicellulose has been filled with cadmium bond vibrations present in areas adjacent to $3623.44 \mathrm{~cm}^{-1}$ and $3677.45 \mathrm{~cm}^{-1}$ [13] showing that there is a reaction of carboxylic functional groups on the corncobs hemicellulose with cadmium.

\subsection{Chelating Ability of Corn Cobs Hemicellulose and Pectin toward Cadmium in $\mathbf{p H} 2$}

Chelating ability of corn cobs hemicellulose and pectin toward cadmium ion is shown in Table 3. The administration of chelating agent to bind distinct cadmium in the $\mathrm{pH} 2$ gives different results.

From Table 3, it can be seen that there is an influence of the type and weight of chelating agent applied. But, in contrast to pectin, with the addition of pectin, the concentration will also increase properly the strap to cadmium ions. On the $100 \mathrm{mg}$ pectin, there has a binding ability of $(20.86 \pm 0.3924) \mathrm{mg}$ cadmium ion or $69.53 \%$, but the $200 \mathrm{mg}$ pectin will give a greater ability around $(25.30 \pm 0.6599) \mathrm{mg}$ cadmium ion or $84.33 \%$ and 300 $\mathrm{mg}$ of pectin bound by an increase of $(26.89 \pm 0.5817)$ mg of cadmium ions or $89.63 \%$. Compared to corn cobs hemicellulose, the average increase of the binding ability is around $4.33 \%-6.61 \%$. The overall number of increased binding ability of pectin is still below the binding ability. It means that a chelating effect of the corn cobs hemicellulose is greater than pectin. The higher the amount of chelating agent showed the higher increase of chelating agent ability. But, in corn cobs hemicellulose, the increase was not in proportional with its amount. It is in accordance with the principle of absorption that the absorption process will end if there is equilibrium between the absorbents combination [18]. Therefore, the weight does not affect a significant absorbance with the
Table 3. Various binding effect of $\mathrm{CCH}$ and pectin for 30 $\mathrm{mg}$ in $25 \mathrm{~cm}^{3}$ cadmium ions.

\begin{tabular}{cccc}
\hline $\begin{array}{c}\text { Chelating } \\
\text { agent }\end{array}$ & Weight & $\begin{array}{c}\text { Cadmium content } \\
\text { in chelating } \\
\text { agent }(\mathrm{mg})\end{array}$ & $\begin{array}{c}\text { Percentage cadmium } \\
\text { ion in chelating } \\
\text { agent }(\%)\end{array}$ \\
\hline \multirow{4}{*}{$\mathrm{CCH}$} & $100 \mathrm{mg}$ & $24.41 \pm 0.6185$ & 81.36 \\
& $200 \mathrm{mg}$ & $25.65 \pm 0.4279$ & 85.50 \\
& $300 \mathrm{mg}$ & $26.68 \pm 0.1490$ & 88.93 \\
\multirow{4}{*}{ Pectin } & $100 \mathrm{mg}$ & $20.86 \pm 0.3924$ & 52.75 \\
& $200 \mathrm{mg}$ & $25.30 \pm 0.6599$ & 81.20 \\
& $300 \mathrm{mg}$ & $26.89 \pm 0.5817$ & 93.47 \\
\hline
\end{tabular}

increasing amount of binding ability of corn cobs hemicellulose for each treatment.

On statistical calculations [20,21], it can be seen that the addition of corn cobs hemicellulose will give an increase to binding effect for cadmium ion. But, it can be proved here that the $\mathrm{CCH}$ given as binding ability to a solution of $30 \mathrm{mg}$ in $25 \mathrm{~cm}^{3}$ of cadmium causes a decline in cadmium content in the solution, meaning that there is a chemical function of the $\mathrm{CCH}$ that can bind cadmium ions. This suggests that the hydroxyl and carboxylic group of the corn cobs hemicellulose causes attraction for cadmium ions to be present in solution.

Based on Table 3, it can be stated that the levels of cadmium are tied with chelating agent in the treatment of the type of interaction and the variation of weight. The chelating agent type shows the same thing with the sole influence on the differences that in chelating agent type there is also difference in the binding of cadmium levels and can be maximized by a given weight of $300 \mathrm{mg}$.

The profile of chelating effect of corn cobs hemicellulose and pectin in Figure 3 shows that the weight will increase the ability of the chelating agent to modify isolation corn cobs hemicellulose and pectin as a whole. It can be seen in Figure 3 that the corn cobs hemicellulose has greater ability than pectin. 
Based on Figure 3 above it can be seen that with the weight of $300 \mathrm{mg}$, pectin has the ability to absorb cadmium ions greater than the $\mathrm{CCH}$. But, in the terms of pharmacology, pectin is used as anti-diarrhea only in doses below $165 \mathrm{mg}$, and if given in doses of $300 \mathrm{mg}$ weight, constipation most likely occurred. Besides as a fiber, $\mathrm{CCH}$ has pharmacological effects to improve the digestive system and is not toxic.

\subsection{Binding Ability Corn Cobs Hemicellulose toward Cadmium with in Vivo}

The corn cobs hemicellulose test with three treatments was carried out for 10 weeks and the results of the test treatments $A_{1}, A_{2}$ and $A_{3}$ are shown in Table 4 .

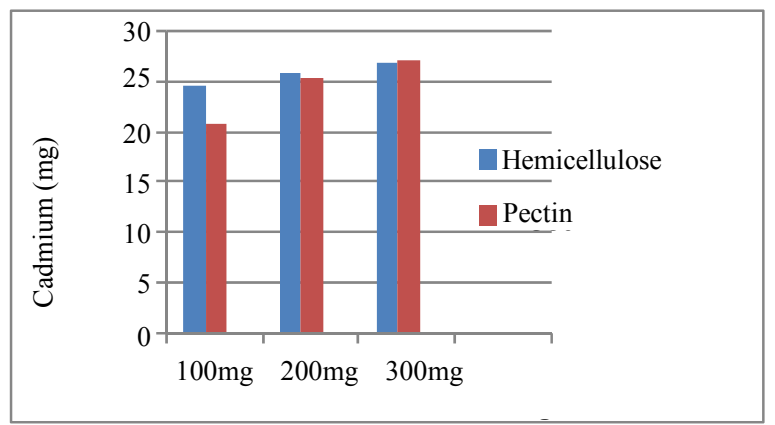

Figure 3. Charts comparison of $\mathrm{CCH}$ and pectin bind to cadmium ions.

Tabel 4. Effect of treatment for 10 weeks on the average blood cadmium levels.

\begin{tabular}{|c|c|c|c|c|}
\hline Week & Treatment & $\mathrm{N}$ & Weight (ppm) & Standard of deviation \\
\hline \multirow{3}{*}{0} & $\mathrm{~A}_{1}$ & 4 & 2.42 & 0.2902 \\
\hline & $\mathrm{A}_{2}$ & 4 & 2.37 & 0.1127 \\
\hline & $\mathrm{A}_{3}$ & 4 & 3.09 & 0.1676 \\
\hline \multirow{3}{*}{2} & $\mathrm{~A}_{1}$ & 4 & 4.32 & 0.5048 \\
\hline & $\mathrm{A}_{2}$ & 4 & 3.96 & 0.3347 \\
\hline & $\mathrm{A}_{3}$ & 4 & 4.46 & 0.2936 \\
\hline \multirow{3}{*}{4} & $\mathrm{~A}_{1}$ & 4 & 3.08 & 0.2927 \\
\hline & $\mathrm{A}_{2}$ & 4 & 3.34 & 0.7862 \\
\hline & $\mathrm{A}_{3}$ & 4 & 2.69 & 0.1706 \\
\hline \multirow{3}{*}{6} & $\mathrm{~A}_{1}$ & 4 & 0.39 & 0.1578 \\
\hline & $\mathrm{A}_{2}$ & 4 & 0.79 & 0.3126 \\
\hline & $\mathrm{A}_{3}$ & 4 & 0.59 & 0.3624 \\
\hline \multirow{3}{*}{8} & $\mathrm{~A}_{1}$ & 4 & 0.21 & 0.0150 \\
\hline & $\mathrm{A}_{2}$ & 4 & 0.50 & 0.2435 \\
\hline & $\mathrm{A}_{3}$ & 4 & 0.42 & 0.3738 \\
\hline \multirow{3}{*}{10} & $\mathrm{~A}_{1}$ & 4 & none & none \\
\hline & $\mathrm{A}_{2}$ & 4 & 0.35 & 0.3070 \\
\hline & $\mathrm{A}_{3}$ & 4 & 0.04 & 0.0526 \\
\hline
\end{tabular}

$\mathrm{A}_{1}: 100 \mathrm{mcg}$ of cadmium, every two days for two weeks and then continued $100 \mathrm{mcg}$ of cadmium and $10 \mathrm{mg}$ hemicellulose. $\mathrm{A}_{2}: 100 \mathrm{mcg}$ of cadmium and $10 \mathrm{mg}$ hemicellulose every two days. $\mathrm{A}_{3}: 10 \mathrm{mg}$ hemicellulose every two days.
Based on the Table 4, it appears from the blood samples taken prior to treatment $\left(\mathrm{W}_{0}\right)$ that the average blood cadmium level is at $(2.63 \pm 0.3893) \mathrm{ppm} / \mathrm{cm}^{3}$, and after the third treatment every other day for 2 weeks there was a decrease in blood cadmium levels as proved in treatment $A_{1}, A_{2}$ and $A_{3}$. This is caused by the influence of carrots eaten an average of 200 grams per day has contained cadmium at $0.02 \mathrm{ppm}$. Thus, if affects the content of cadmium in the blood of rabbits. Under the same conditions, the examination of the fourth week of a decline in cadmium levels in all treatments showed a decrease of blood cadmium levels in rabbits. In other same conditions, results showed a decline in cadmium levels and continued until measurements in ten weeks. The treatment was then stopped because the results of the analysis of blood cadmium levels in some rabbits were not detected and the mean cadmium levels were $(0.13 \pm 0.2299)$ $\mathrm{ppm} / \mathrm{cm}^{3}$. This means that the administration of $10 \mathrm{mg}$ corn cobs hemicellulose for 10 weeks can reduce cadmium levels of $2.50 \mathrm{ppm}$ or $95.05 \%$. On the other hand, F test [21] results show that the statistical analysis before treatment $\left(\mathrm{W}_{0}\right)$ to check on $\mathrm{W}_{10}$ shows no significant difference. This means that the process of the treatment of three types of treatment for 10 weeks can reduce blood cadmium levels in rabbits. In other words, corn cobs hemicellulose can be used as an ingredient to reduce cadmium levels in the blood as shown graphically in Figure 4.

Based on the Figure 4, it appears that duration of treatment affects the levels of cadmium in the blood. The results of blood tests at the end of $\mathrm{W}_{2}$ show an increase in levels of cadmium on, $\mathrm{A}_{1}, \mathrm{~A}_{2}$ and $\mathrm{A}_{3}$ treatment. But, in the $\mathrm{W}_{4}$ week there had been a decrease in the blood and the decline continued until the $\mathrm{W}_{10}$. Treatment was stopped due to blood cadmium levels in several rabbits are not detected meaning that the administration of $10 \mathrm{mg}$ corn cobs hemicellulose with a period of 10 weeks can reduce exposure to cadmium levels in the blood. It also means

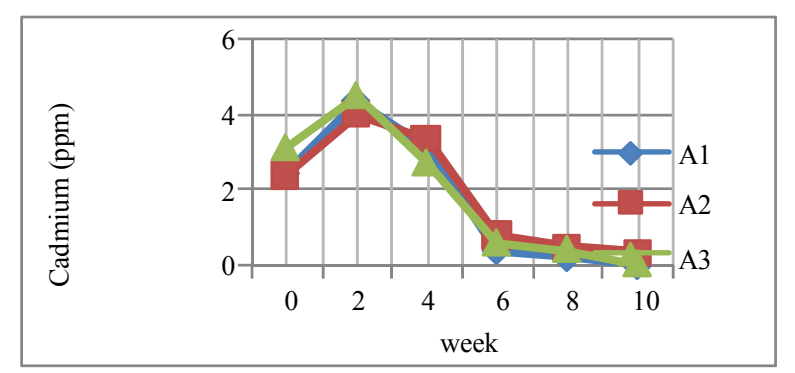

Figure 4. Graphics the relationship between time of administration and reduction of cadmium content in the blood. Description: $A_{1}: 100 \mathrm{mcg}$ cadmium, every two days for two weeks and then continued 100 mcg of cadmium and $10 \mathrm{mg}$ corn cobs hemicellulose. $A_{2}: 100$ mcg of cadmium and $10 \mathrm{mg}$ corn cobs hemicellulose every two days. $A_{3}: 10 \mathrm{mg}$ corn cobs hemicellulose g every two days. 
when corn cobs hemicellulose is given in greater weight, it will affect the essential minerals needed by the body in large quantities such as calcium, iron, zinc, sodium, potassium, etc. Therefore, it is worried that it would also reduce levels of these essential minerals.

\section{Conclusions}

Modified isolation of corn cobs hemicellulose yields $12.04 \%$ of hemicelluloses and characteristics of the hydroxyl group with vibrational infrared (FTIR) methods providing vibrational hemicellulose in the region of 1820 - $1600 \mathrm{~cm}^{-1}$. The carbonyl group provides vibrational hemicellulose widened near $3400-2400 \mathrm{~cm}^{-1}$ and has finger print at $1500-500 \mathrm{~cm}^{-1}$. Corn cobs hemicelluloses have the ability to bind cadmium in $\mathrm{pH} 2$ and to increase ability influenced by the weight. The highest ability is shown by the $300 \mathrm{mg}$ corn cobs hemicelluloses with binding ability at $(26.68 \pm 0.1490) \mathrm{mg}$ to $30 \mathrm{mg}$ of cadmium solution, or $88.93 \%$. Corn cobs hemicellulose can be used as a chelating agent of metal ions.

The results of in vivo tests showed that $10 \mathrm{mg}$ of $\mathrm{CCH}$, given every other day for 10 weeks, was able to reduce cadmium levels of $2.50 \mathrm{ppm}$ or $95.05 \%$ from the initial levels of $(2.63 \pm 0.3893) \mathrm{ppm} / \mathrm{cm}^{3}$. It means that corn cobs hemicellulose can be used to reduce levels of blood cadmium.

\section{REFERENCES}

[1] W. C. Prozialeck, J. R. Edward, W. N. Nebert, J. M. Woods, A. Barchowsky and W. D. Atchison, "The Vascular System as a Target of Metal Toxicity," Toxicology Sciences Journal, Vol. 102, No. 2, 2008, pp. 207-218. doi:10.1093/toxsci/kfm263

[2] S. J. Casas and J. Dan Sordo, "Lead Chemistry, Analytical Aspects," Environmental Impact and Health Effects, 2006, pp. 3-5.

[3] S. Jickel and A. Negrusz, "Clarke's Analytical Forensic Toxicology," 3th Edition, Pharmaceutical Press, Chichago, 2008.

[4] R. Caprita, A. Caprita and C. Dan Julean, "Biochemical Aspect of Non-Polysaccarides," Animals Sceinces and Biotechnologies, Vol. 43, No. 1, 2010, pp. 1-4.

[5] A. M. Karaaslan, M. A. Tshabalala and D. G. Buschle, "Wood Hemisellulose/Chitosan-Basedsemi-Interpenetrating Networks Hydrogels: Mechanical, Swelling and Control Drug Release Properties," Journal of Bioresources, Vol. 5 No. 2, 2010, pp. 1036-1054.

[6] M. P. Yadav, D. B. Johnston and K. B. Hicks, "Structural Characterization of Corn Fiber Gums from Coarse and Fine Fiber and a Study of Their Emulsifying Properties," Journal of Agricultural and Food Chemistry, Vol. 55, No.

\section{5, 2007, pp. 6366-6371. doi:10.1021/jf070024q}

[7] C. B. Saha, "Hemicellulose Bioconversion," Journal of Microbiologie Biotechnologie, Vol. 30 No. 16, 2003, pp. 279-291.

[8] A. E. Silva, H. R. Marcelino, M. C. S. Gomes, E. E. Oliveira, T. Nagashima Jr. and E. S. T. Egito, "Xylan, a Promising Hemicellulose for Pharmaceutical Use," Products and Applications of Biopolymers Journal, 2008, pp. 6082.

[9] E. Purwoningsih, "Effect of Molecular Weight Chitosan against Levels Plumbum $(\mathrm{Pb})$ Blood and Enzyme Activity-Alad $\delta$ (Delta Aminolevulinic Acid Dehydratase) Albino Mice (Mus Musculus L) Healthcare,” Master Thesis, University of North Sumatra, Medan, 2008.

[10] I. M. Tarigan, "Analysis of the Applicability of Chitosan and Chitosan Beads as Adsorbents Standard Solution to Lower Levels of Iron (Fe) and Aluminum (Al) by Atomic Absorption Spectrophotometry," Master Thesis, University of North Sumatra, Medan, 2008.

[11] W. W. Wong, F. M. A. Abbas, M. T. Liong and M. E. Azhar, "Modification of Durian Ring for Improved Biosorbent Ability," International Food Research Journal, Vol. 15, No. 3, 2008, pp. 363-365.

[12] S. Dumitriu, "Polysaccharides: Structural Diversity Dan Functional Versatility," Marcel Dekker, New York, 2005.

[13] N. Richana, T. T. Irawadi and A. M. Nur, "The Extraction of Hemicellulose from Corn Cobs," Postharvest Journal, Vol. 4, No. 1, 2007, pp. 38-43.

[14] H. G. Britthin, "Spectroscopy of Pharmaceutical Solids," Center for Pharmaceutical Physis Taylor and Francis Group, New York, 2006. doi:10.1201/9780849361333

[15] C. A. Moffat, D. M. Osellton and B. Widdop, "Clarke's Analysis of Drugs and Poisons," Pharmaceutical Press, London, 2005.

[16] J. Szkoda and J. Zmudzki, "Determination of Lead and Cadmium in Biological Material by Graphite Furnace Atomic Absorption Spectrometry Method," Buletin Veterinair Institute, Vol. 49, 2005, pp. 89-92.

[17] J. B. Smith and S. Mangkoewidjojo, "The Maintenance, Breeding and Use of Experimental Animals in the Tropics," University of Indonesia Publisher, Jakarta, 1988.

[18] J. Basset, R. C. Denny, B. H. Jeffrey and J. Mendham, "Vogel's Textbook of Quantitative Inorganic Analysis Including Elementary Instrumental Analysis," Translation, EGC Book Medical Publishers, Jakarta, 1994.

[19] W. Haryadi, “Analytical Chemistry,” PT Gramedia, Jakarta, 1990.

[20] R. G. Pearson, "Chemical Hardness and Density Functional Theory," Journal of Chemicals Sciences, Vol. 117, No. 5, 2005, pp. 369-377. doi:10.1007/BF02708340

[21] R. G. D. Steel and J. H. Torrie, "Principles and Procedures Statistics A Biometric Approach,” No. 2 PT Gramedia Pustaka Husada, Jakarta, 1991. 